\title{
Optimization of transport routes based on environmental indicators
}

\author{
Sergey Kuren ${ }^{1}$, Galina Galchenko ${ }^{1}$, Sergey Popov ${ }^{1, *}$, Julianna Marchenko ${ }^{1}$, Nikolai Dontsov ${ }^{1}$, \\ and Dmitriy Drozdov ${ }^{2}$ \\ ${ }^{1}$ Don State Technical University, 344003, 1, Gagarin sq., Rostov-on-Don, Russia \\ ${ }^{2}$ Southern Federal University, 344006, 105/42, Bolshaya Sadovaya st., Rostov-on-Don, Russia
}

\begin{abstract}
Air pollution monitoring in Rostov-on-Don and Rostov region is considered. The excess of the concentration of suspended solids over the national average is shown, especially near motorways and the busiest intersections. On the example of one intersection, field observations were carried out, and based on the developed computer programs, calculation of the main transport characteristics, the vehicle queue length at different phases of traffic light switching was carried out. The necessity of installing a "smart" (adaptive) traffic light is shown. The developed software products can be used to improve the organization of traffic flows and as a computer laboratory when teaching students in the specialty "Organization of transport processes".
\end{abstract}

\section{Introduction}

The problem of optimizing the movement of urban transport is acute for the departments of large cities. Transportation problems in metropolitan areas, such as congestion at intersections, lead to high levels of polluting emissions when a car engine is idling or running slowly. Due to the high concentration of vehicles in megalopolises, the air is depleted in oxygen and polluted by emissions from the combustion of petroleum products [1-6]. From the air, harmful products get into the water and the water environment is polluted, the ecological system is disrupted, natural and climatic conditions change. In terms of environmental damage, vehicles are leading in all types of negative impact: air pollution $-95 \%$, noise $-49.5 \%$, climate impact - $68 \%$. The main cause of air pollution is incomplete and uneven combustion of fuel. Only $15 \%$ of it is spent on driving a car, and $85 \%$ "flies into the wind." The exhaust gases of an internal combustion engine contain over 170 harmful components, of which about 160 are hydrocarbon derivatives.

\section{Environmental monitoring}

For the Rostov region, the problem of air pollution is currently urgent, especially in large cities. Since 2019, 12 cities of the Rostov Region have been monitored for the state of

\footnotetext{
${ }^{*}$ Corresponding author: spopov1957@yandex.ru
} 
atmospheric air. A high level of air pollution in the Rostov region is observed in Rostov-onDon and Novocherkassk.

In Rostov-on-Don monitoring is carried out at seven stationary stations of the State network for observing the state of the environment of the Rostov Hydrometeorological Center, including at four stations of the main and three stations of the additional (municipal) network.

Analyzed data for the period of 2008-2016. The study revealed a regular change in the chemical composition of emissions into the atmosphere of the region. At the beginning of this period, the amount of pollutants in general in the Rostov region amounted to 636.344 thousand tons, and in $2016-629.3$ thousand tons. The volumes of emissions remained approximately at the same level, while the qualitative composition of emissions changed.

Analyzing the pollution of city districts, it should be noted that the highest level of pollution, primarily with such impurities as benzpyrene, formaldehyde, nitrogen oxides and dust, is typical for the central part of city near motorways. Emissions from vehicles dominate in the total amount of pollutants entering the atmosphere (about $70 \%$ ), as evidenced by the chemical composition of emissions. The results of monitoring pollution by suspended solids (dust), carbon oxides, nitrogen dioxide, nitrogen oxides and formaldehyde are shown in Fig. 1-2. If we take different substances separately, then with respect to sulfur dioxide, nitrogen dioxide, nitrogen oxide and carbon dioxide, everything is relatively calm, since on average per year their presence in the air does not exceed the maximum permissible concentration.

The analysis of the conducted monitoring shows the excess of concentration of suspended solids over the national average. The level of pollution by carbon oxides, nitrogen oxides, nitrogen dioxide is also higher than the national average. Its content in the air exceeds the norm by an average of 1.7 times, and in the center of Rostov-on-Don - 2.6 times. There is also an average annual excess for formaldehyde and hydrogen fluoride. The content of phenol, soot, ammonia and solid fluorides in the air is below the maximum permissible concentrations.

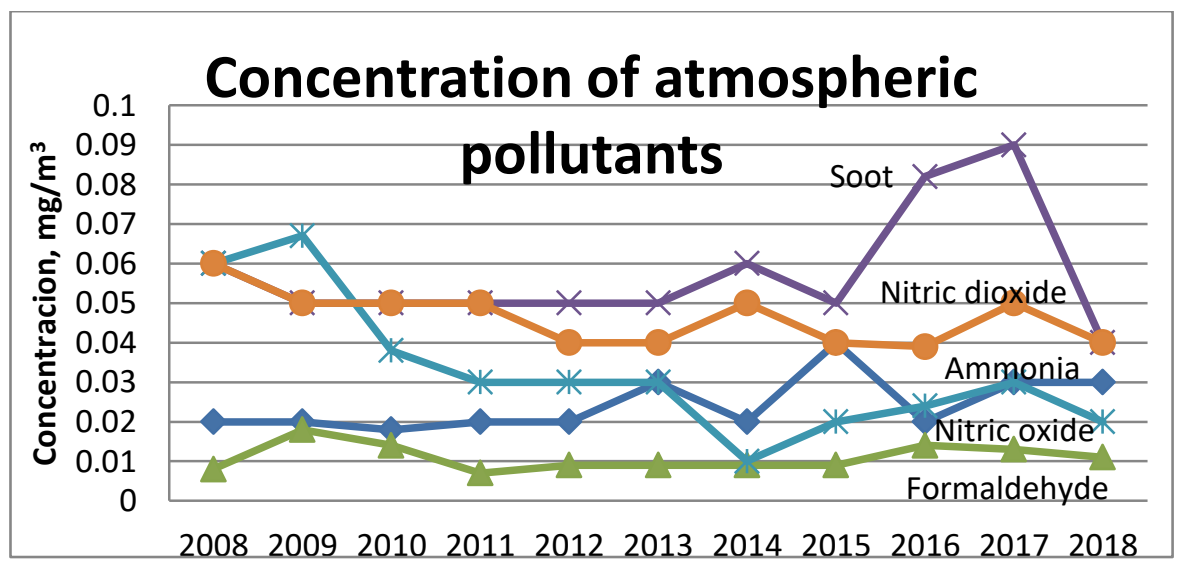

Fig. 1. Concentration of chemical air pollutants in Rostov-on-Don for 2008-2018 


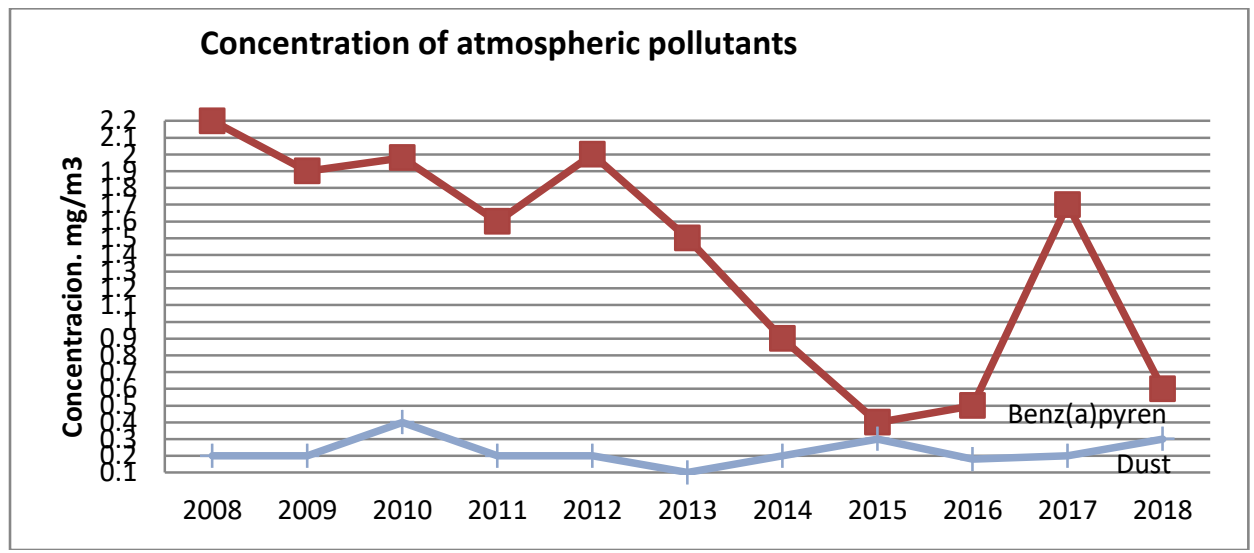

Fig. 2. Concentration of chemical air pollutants in Rostov-on-Don for 2008-2018

In most cities of the Rostov region for the period 2008-2016 there is an increase in the level of air pollution with soot, carbon monoxide, nitrogen oxides, nitrogen dioxide, phenol and formaldehyde, which is directly related to a significant increase in the fleet of vehicles in use. At the same time, there is a decrease in the level of pollution: sulfur dioxide, nitrogen oxides, hydrogen sulfide and benzopyrene, which clearly demonstrates the result of the decisions taken at the state level to restrict import of used cars and to improve quality of hydrocarbon fuels [7-14].

The chemical composition of air emissions indicates a significant contribution of road transport to emissions of pollutants. As can be seen from the diagrams presented above, the share of environmental damage from vehicles is steadily increasing.

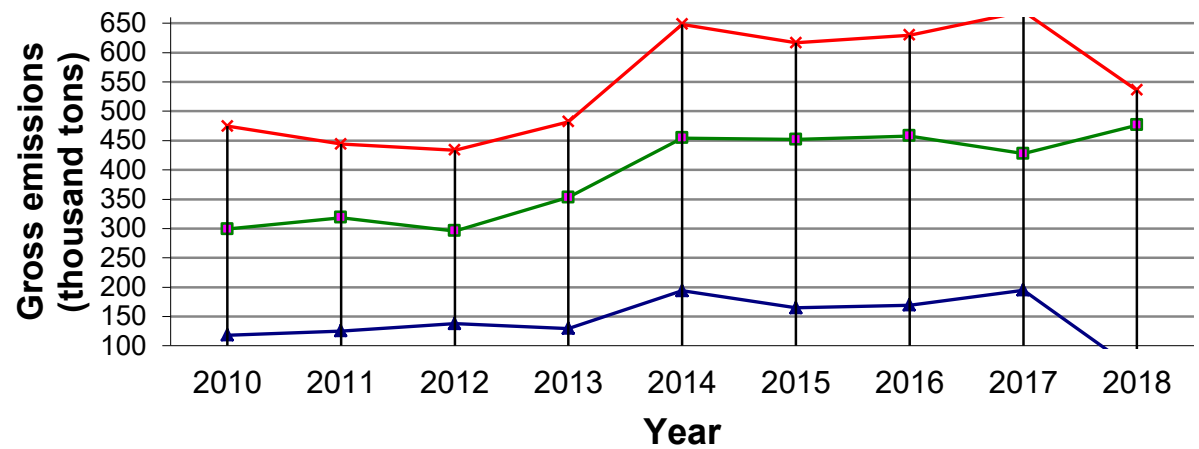

Fig. 3. Dynamics of gross emissions of pollutants from stationary sources (blue), vehicles (green) and all sources (red) of atmospheric pollution in the Rostov region in 2010-2018.

The diagram (Fig. 4) shows the relationship between the contributions of stationary and mobile sources in Rostov-on-Don for the period 2010-2018. 


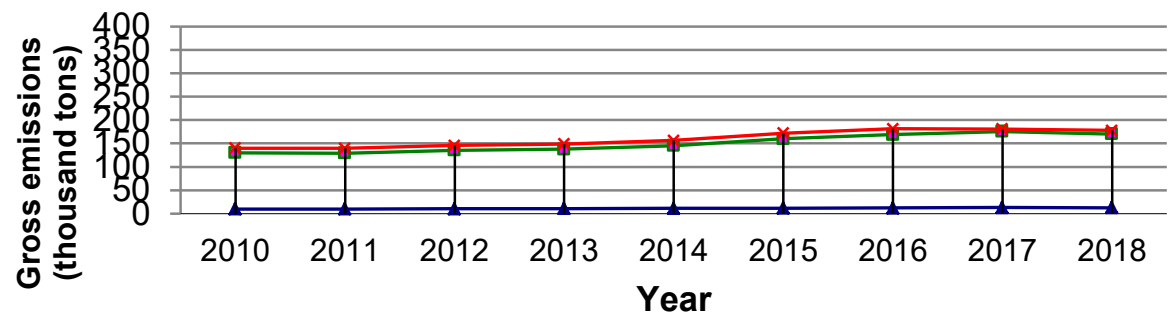

Fig. 4. Dynamics of gross emissions of pollutants from stationary sources (blue), vehicles (green) and all sources (red) of atmospheric pollution in the Rostov region in 2010-2018.

The volume of emissions into the atmosphere from road transport directly depends on the size of the car park of a city or region, on its qualitative composition, age of vehicles, their capacity, technical condition.

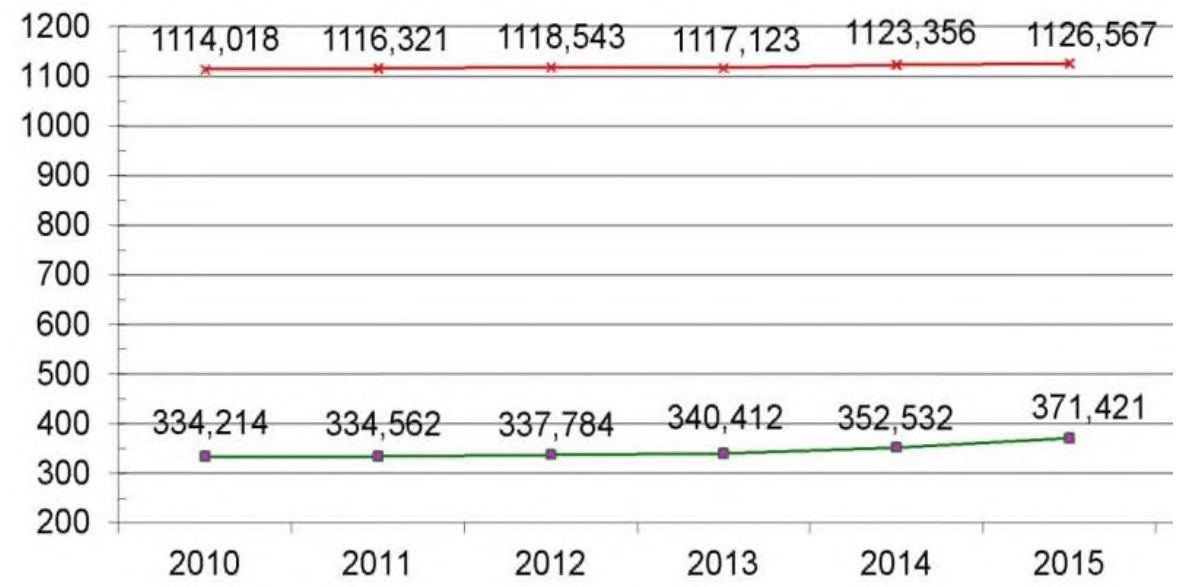

Fig. 5. Growth in the number of cars (thousand units) in the Rostov region and Rostov-on-Don in 2010-2015.

One of the solutions to the problem of pollution of the city with combustion products is the organization of traffic light regulation taking into account the current transport situation. The decision to install a smart traffic light system should be based on an analysis of the traffic situation at the intersection. For the analysis of the transport situation, such approaches as field observations are widely used, which make it possible to determine the structure and number of vehicles, software systems and technical means [15-22].

\section{Information and mathematical approach to the calculation of the main transport characteristics of busy intersections}

Implementation of the results of mathematical modeling leads to an improvement in traffic organization [2-4]. A large number of scientific articles are devoted to various concepts of traffic flow modeling [1-6]. One of the approaches is based on abstraction, when a large city with its developed road network is represented by a kind of force field. A point placed in a force field, is acted upon by a force, which magnitude and direction depends only on coordinates and time. This approach is called the method of electrodynamic modeling [2329]. On the basis of this method, the authors have developed a computer program "Material 
flow", with the help of which the calculation of the main transport characteristics (intensity, traffic intensity and resistance to movement) of the most loaded intersections in Rostov-onDon (Fig. 6a) was carried out in order to determine the need for installation of "smart" traffic lights. As an example, graphs of the dependences of the main transport characteristics of the intersection of Nemirovich-Danchenko st. - Sheboldaeva st., Rostovon-Don (Fig.6b). Fig. 7-8 shows the results of field observations and calculations of main transport characteristics [30-31].

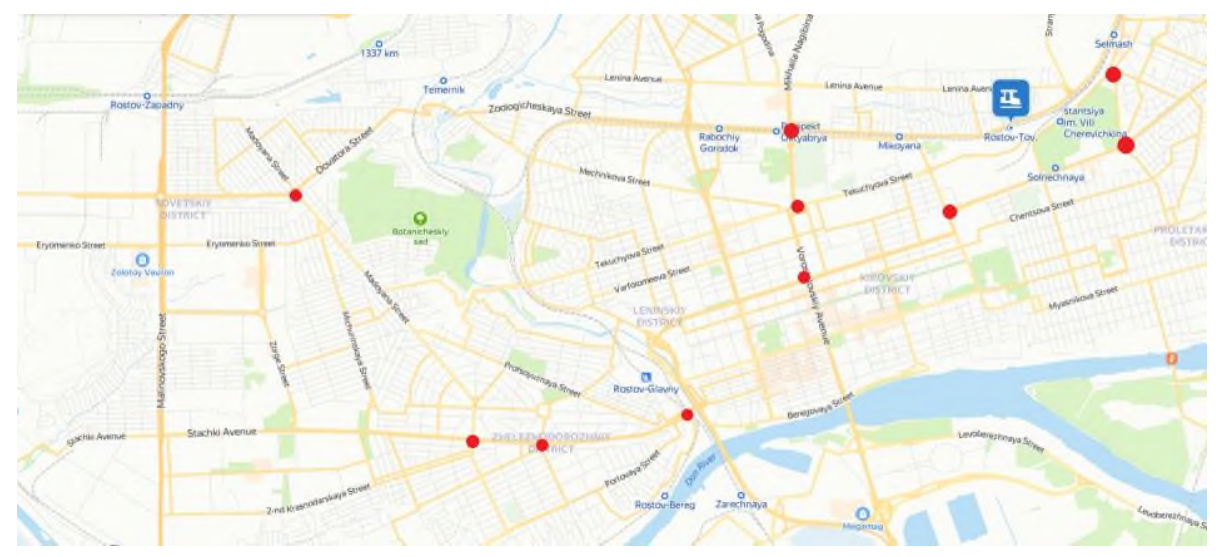

Fig.6. a) Intensively loaded intersections of Rostov-on-Don.

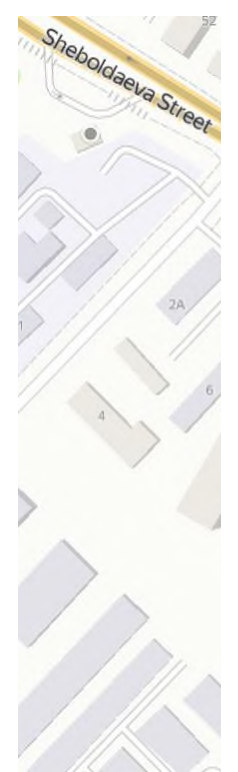

Fig 6. b) Map intersection Danchenko st. Rostov-on-Don

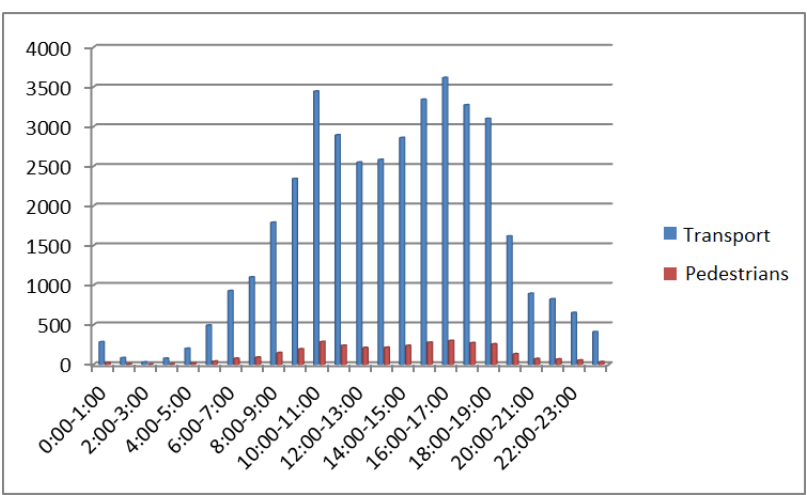

of the

Nemirovich-

Sheboldaeva st., 


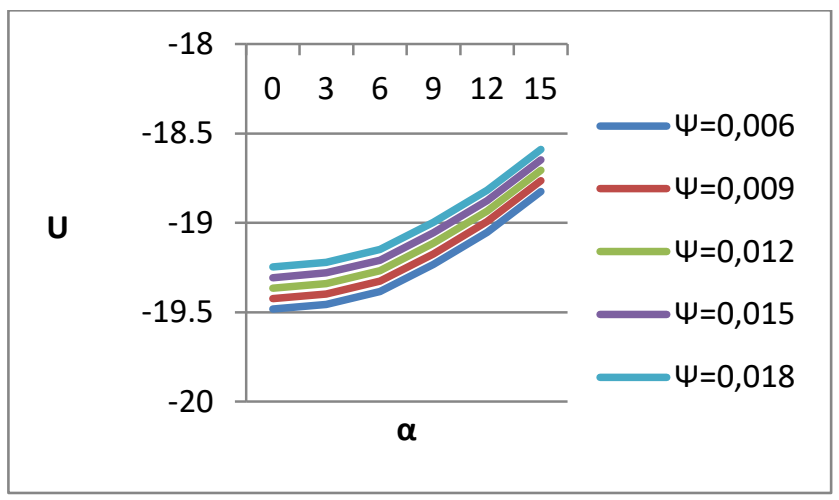

Fig. 7. a) Field observations of traffic intensity at an intersection. b) Voltage dependence U ТП from the slope of the track $\alpha$ under various weather conditions $\psi$

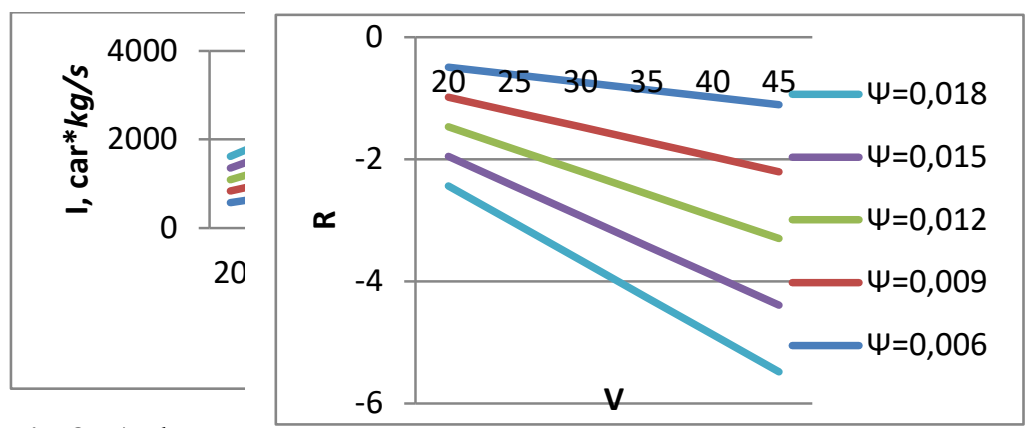

Fig. 8. a) The intensity I on the speed V and the number of vehicles. b) Dependence of the resistance of movement $\mathrm{R}$ on the speed $\mathrm{V}$ under various weather conditions $\psi$

\section{The need to install an adaptive traffic light}

The analysis of the calculations shows that for a given traffic intensity, resistance to traffic and traffic intensity are quite large, which indicates the need to improve the organization of traffic. One approach is to install a smart traffic light. An important factor in reducing environmental pollution is to reduce the queue of vehicles in front of traffic lights. With the help of the "Green Wave" computer program developed by the authors, created on the basis of the cellular automata method, a comparative analysis of the queue length at a given intersection was carried out with different traffic light control algorithms and different traffic flow parameters. There were considered and analyzed the two types of traffic light algorithms: adaptive smart algorithm (AT-1) and traffic light with a fixed cycle of signal switching (FC). A computational experiment on comparing the effect of the type of traffic light switching algorithm on the queue length at a traffic light was carried out for four values of the load of intersecting roads: $50 \% / 50 \% ; 60 \% / 40 \% ; 70 \% / 30 \% ; 80 \% / 20 \%$. The computational experiment took $\mathrm{T}=$ 600 steps. To change the flow density for each load option, the value of the "Flow rate" parameter was changed in the program and was taken equal to: 150, 160, 170, 190 cars per direction. [31-32] 


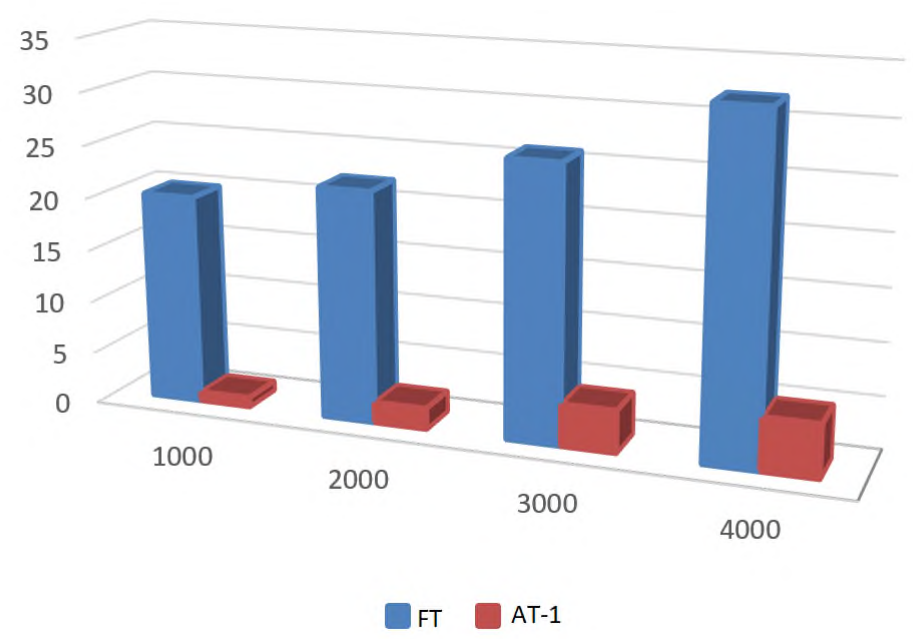

Fig. 9. Histogram comparing the dependence of the average queue length on the traffic intensity of vehicles at an intersection with a "smart" algorithm (AT-1) and a fixed traffic light switching cycle (FC) with a flow distribution of $60 \% 40 \%$.

From the graph shown in Fig. 9, it follows that with equal parameters, the "smart" traffic light gives a significant reduction in the queue length and waiting time at the intersection in comparison with the traffic light with a fixed cycle.

\section{Conclusions}

The monitoring of pollutants in Rostov-on-Don, the use of mathematical methods and computer programs developed on their basis, allows us to make recommendations for the installation of "smart traffic lights" on the busy sections of the transport arteries of the metropolis, which helps to reduce the length of the queue of vehicles at traffic lights, reducing exhaust emissions and, accordingly, improving the environmental situation. In addition, this approach and the developed software products can be used for educational purposes as a student laboratory for optimization and modeling of transport processes for students and undergraduates in the direction of "Organization of transport processes".

\section{References}

1. A. A. Korotky, S. I. Popov, G. A. Galchenko, Ju. V. Marchenko, D. S. Drozdov, The use of SmartBox container for agrobusiness logistic processes optimization. XIII International Scientific and Practical Conference "State and Prospects for the Development of Agribusiness - INTERAGROMASH 2020»: E3S Web of Conferences, 175, 13019 (2020) doi.org/10.1051/e3sconf/202017513019

2. V. V. Ivanov, N. P. Pogorelov, N. S. Dontsov, Y. N. Denisenko, AIP Conference Proceedings, 2188, 020005 (2019) doi.org/10.1063/1.5138379

3. A. Lerer, G. Makeeva, G. Galchenko, RSEMW8792726, 261-264 (2019) DOI: 10.1109/RSEMW.2019.8792726

4. D. Gubsky, A. Kleschenkov, G. Galchenko, RSEMW, 344-347 (2019) DOI: 10.1109/RSEMW.2019.8792726 
5. M. N. Moskovsky, A. V. Kovaleva, S. G. Kuren, ARPN Journal of Engineering and Applied Sciences, 12(22), 6414 (2017)

6. A. A. Korotky, E. V. Marchenko, S. I. Popov, Ju. V. Marchenko, N. S. Dontsov, Theoretical foundations of modeling the process of transport vehicles steel ropes structural defects formation. XIII International Scientific and Practical Conference "State and Prospects for the Development of Agribusiness - INTERAGROMASH 2020»: $E 3 S \quad W e b \quad$ of Conferences, 175, $05018 \quad$ (2020) doi.org/10.1051/e3sconf/202017505018

7. V. V. Ivanov, S. I. Popov, N. S. Dontsov, G. E. Ekinil, Ju. A. Oleynikova, Ju. N. Denisenko, Mechanical coating formed under conditions of vibration exposure. XIII International Scientific and Practical Conference "State and Prospects for the Development of Agribusiness - INTERAGROMASH 2020»: E3S Web of Conferences, 175, 05023 (2020) doi.org/10.1051/e3sconf/202017505023

8. A. F. Apalkov, S. A. Apalkov, S. G. Kuren, S. I. Popov, N. S. Dontsov, Soil resistance in the process of dams' irrigation canals profiling. XIII International Scientific and Practical Conference «State and Prospects for the Development of Agribusiness INTERAGROMASH 2020»: E3S Web of Conferences, 175, 09005 (2020) doi.org/10.1051/e3sconf/202017509005

9. O. V. Beluzhenko, S. G. Kuren, S. I. Popov, N. S. Dontsov, Social and psychological attitudes of students at the different stages of studying. XIII International Scientific and Practical Conference «State and Prospects for the Development of Agribusiness INTERAGROMASH 2020»: E3S Web of Conferences, 175, 15017 (2020) doi.org/10.1051/e3sconf/202017515017

10. V. V. Ivanov, S. I. Popov, E. M. Selemeneva, N. T. Babazhanov, Study of technological characteristics of the process of formation of vibration mechanochemical oxide coating. XV International scientific-technical conference «Dynamics of technical systems» (DTS-2019): AIP Conference Proceedings, 2188, 020015 (2019) doi.org/10.1063/1.5138389

11. V. V. Ivanov, S. I. Popov, Ju. V. Marchenko, E. V. Marchenko, N. S. Dontsov, S. A. Timofeev, Thickness of vibrational mechanochemical solid-lubricant coating in friction pairs of transport engineering products. XII International Scientific Conference on Agricultural Machinery Industry (INTERAGROMASH 2019): IOP Conference Series: Earth and Environmental Science, 403 (2019) doi:10.1088/1755$1315 / 403 / 1 / 012115$

12. A. A. Korotky, E. V. Marchenko, V. V. Ivanov, S. I. Popov, Ju. V. Marchenko, N. S. Dontsov, Model of forming vibration mechanochemical solid lubrication coating on surface of steel rope. XII International Scientific Conference on Agricultural Machinery Industry (INTERAGROMASH 2019): IOP Conference Series: Earth and Environmental Science, 403 (2019) doi:10.1088/1755-1315/403/1/012116

13. A. A. Kotesova, S. V. Teplyakova, S. I. Popov, F. C. Kopylov, Ensuring assigned fatigue gamma percentage of the components. International Scientific Conference "Construction and Architecture: Theory and Practice of Innovative Development» (CATPID-2019): IOP Conference Series: Materials Science and Engineering, 698 (2019) doi:10.1088/1757-899X/698/6/066029

14. N. N. Nikolaev, Yu. V. Marchenko, S. K. Filatov, Research and modeling of the taxi service in small towns. International Scientific Conference "Construction and Architecture: Theory and Practice of Innovative Development» (CATPID-2019): IOP Conference Series: Materials Science and Engineering, 698 (2019) doi:10.1088/1757899X/698/6/066027 
15. V. Ilyasov, B. Meshi, D. Pham, C. Nguyen, O. Holodova, T. Zhdanova, I. Ershov, N. Prutsakova, I. Popova, Springer Proceedings in Physics, 207, 127-144 (2018) doi:10.1007/978-3-319-78919-4

16. A. Altybayev, A. Zhanbyrbayev, B. Meskhi, D. Rudoy, A. Olshevskaya, A. Prohorova, E3S Web of Conferences, 135, 01078 (2019) https://doi.org/10.1051/e3sconf/201913501078.

17. B. Meskhi, B. Golev, V. Efros, D. Rudoy, A. Olshevskaya, V. Zhurba, Y. Chayka, E3S Web of Conferences, 135, 01083 (2019) https://doi.org/10.1051/e3sconf/201913501083

18. A. A. Kostoglotov, D. S. Andrashitov, A. S. Kornev, S. V. Lazarenko, A Method for Synthesis of Algorithms to Estimate the Dynamic Error of Measurement System Software on the Basis of the Combined Maximum Principle. Measurement Techniques, 62, 497-502 DOI: 10.1007/s11018-019-01652-8 (2019)

19. S. V. Lazarenko, A. A. Kostoglotov, Synthesis of Adaptive Tracking Systems Based on the Hypothesis of Stationarity of the Hamiltonian on the Switching Hypersurface. Journal of Communications Technology and Electronics, 62(2), 123-127 (2017) DOI: 10.1134/S1064226917020061.

20. A. A. Kostoglotov, I. V. Pugachev, S. Lazarenko, Method of synthesis of multi-mode control under the expected uncertainty using the analysis of the phase-space decomposition on the basis of the generalized power maximum condition.AIP Conference Proceedings (2019) DOI: https://aip.scitation.org/doi/abs/10.1063/1.5138398. DOI: 10.1063/1.5138398.

21. G. Parkhomenko, S. Kambulov, A. Olshevskaya, A. Babadzhanyan, N. Gucheva, I. Mekhantseva, IOP Conf. Series: Earth and Environmental Science, 403 (2019) 012144 IOP Publishing doi:10.1088/1755-1315/403/1/012144

22. V. Kasyanov, V. Deryushev, L. Shulkin, E. Kosenko, A. Kotesova, MATEC Web of Conferences, 224, 02107 (2018) doi.org/10.1051/matecconf/201822402107

23. T. Rogovenko, M. Zaitseva, Matec Web of Conference, 106, 08011 (2017) doi.org/10.1051/matecconf/201610608011

24. N. N. Yazvinskaya, N. E. Galushkin, D. N. Galushkin, B. Yu. Kalmykov, International Journal of Electrochemical Science, 15(1), 412-423 (2020)

25. B. Yu. Kalmykov, S. G. Stradanchenko, A. Y. Sirotkin, A. S. Garmider, Y. B. Kalmykova, ARPN Journal of Engineering and Applied Sciences, 11(17), 1020510208

26. I. Y. Visotski, N. A. Ovchinnikov, I. M. Petriashvili, Y. B. Kalmikova, B. Yu. Kalmykov, ARPN Journal of Engineering and Applied Sciences, 10(12), 5150-5156 (2015)

27. B. Yu. Kalmykov, N. A. Ovchnnikov, O. M. Kalmikova, I. K. Guguyev, I. V. Kushnariva, ARPN Journal of Engineering and Applied Sciences, 10(10), 4366-4371 (2015)

28. N. A. Ovchinnikov, B. Yu. Kalmykov, S. G. Stradanchenko, E. A. Kozyreva, O. V. Chefranova, ARPN Journal of Engineering and Applied Sciences, 10(22), 1051110522 (2015)

29. B. Yu. Kalmykov, N. A. Ovchinnikov, O. M. Kalmikova, V. I. Jigulskii, Y. G.Yurshin, ARPN Journal of Engineering and Applied Sciences, 10(8), 3793-3797 (2015)

30. A. Altybayev, A. Zhanbyrbayev, B. Meskhi, D. Rudoy, A. Olshevskaya, A. Prohorova, E3S Web of Conferences, 135, $01078 \quad$ (2019) https://doi.org/10.1051/e3sconf/201913501078 
31. I. Bozhko, G. Parkhomenko, S. Kambulov, A. Boyko, V. Kolodkin, M. Magomedov, D. Rudoy, E3S Web of Conferences, 175, 05025 (2020) INTERAGROMASH 2020 https://doi.org/10.1051/e3sconf/202017505025

32. G. Parkhomenko, I. Bozhko, S. Kambulov, A. Boyko, O. Polushkin, V. Lebedenko, A. Beskopilniy, A. Olshevskaya, E3S Web of Conferences, 175, 09006 (2020) INTERAGROMASH 2020 https://doi.org/10.1051/e3sconf/202017509006 